\title{
Georeferenced cartography dataset of the La Fossa crater fumarolic field at Vulcano Island (Aeolian Archipelago, Italy): conversion and comparison of data from local to global positioning methods
}

\author{
Paolo Madonia ${ }^{1, \star}$, Giovannella Pecoraino ${ }^{1}$, Carmelo Sammarco ${ }^{2}$ \\ ${ }^{1}$ Istituto Nazionale di Geofisica e Vulcanologia, sezione di Palermo, Palermo, Italy \\ ${ }^{2}$ Università degli Studi di Palermo, Dipartimento DiSTeM, Palermo, Italy
}

\author{
Article history \\ Received December 22, 2010; accepted May 7, 2011. \\ Subject classification: \\ Geochemical data, Volcano monitoring, Volcanic risk, Fumarole, GPS, Map, Vulcano Island.
}

\begin{abstract}
The present study illustrates the procedures applied for the coordinate system conversion of the historical fumarole positions at La Fossa crater, to allow their comparison with newly acquired global positioning system (GPS) data. Due to the absence of ground control points in the field and on both the old Gauss Boaga and the new UTM WGS 1984 maps, we had to model the transformation errors between the two systems using differential GPS techniques. Once corrected, the maps show a residual Easting shifting, due to erroneous georeferencing of the original base maps; this is corrected by morphological comparative methods. The good correspondence between the corrected positions of the historical data and the results of the new GPS survey that was carried out in 2009 highlights the good quality of the old surveys, although they were carried out without the use of accurate topographical instruments.
\end{abstract}

\section{Introduction}

Vulcano Island (Figure 1) is the southernmost island of the Aeolian Archipelago (southern Tyrrhenian Sea, Italy), which is made up of seven back-arc volcanic islands that are related to the subduction of the African Plate under the European Plate [Barberi et al. 1974]. The study area is located in the northern sector of the island, inside the topographic depression of the La Fossa caldera, within which the La Fossa cone, a small stratovolcano with an altitude of $391 \mathrm{~m}$ a.s.l. and base diameter of about $1 \mathrm{~km}$ (Figure 1), has grown over the past 6000 years [Ventura 1994].

The last eruption at the La Fossa cone occurred in 1888. This lasted two years and was characterized by the deposition of fall-out products of even large dimensions. Since the last eruption, Vulcano Island has been characterized by fumarolic activity, which has been mainly concentrated in the inner northern flank of the La Fossa cone. The fumarolic surface has increased from $50 \mathrm{~m}^{2}$ in 1983 to more than $2400 \mathrm{~m}^{2}$ in 1995. A sharp increase in the surface expansion rate of the fumaroles (up to $1.5 \mathrm{~m}^{2}$ / day) has occurred before (and during) episodes of volcanic unrest [Italiano and Nuccio 1992, Italiano et al. 1998, Bukumirovic et al. 1997]. These authors hypothesized a relationship between variations in the volcanic activity and the geometric distribution of the fumarolic field. For this reason, the reconstruction of the space-time evolution of the fumarolic field represents one of the methods used for monitoring of the volcanic activity. Initially, the relative positions of reference rocks and fumarole shapes were determined by trilateration and by trigonometric, differential and reciprocal leveling. Their absolute positions in the field were determined using a theodolite and they were referred to a trigonometric point. The fumaroles were then hand drawn. During the 1990's, data were processed within a geographic information system (GIS) (Arc/Info), to georeference the digitized topographic maps of the crater area and for the management of geographical (exhaling areas) and steam output data [Bukumirovic et al. 1997].

The crisis of 2004 [Granieri et al. 2006] re-proposed the actuality of fumarolic field mapping and the consequent need for comparisons of the old surveys that were acquired with fast topographical methods with new data derived by modern global positioning system (GPS) techniques.

The main problem is the lack of analytical compatibility between the reference system of the old maps, which refer to the Gauss-Boaga Italian national system, and the WGS1984 native coordinate system for GPS receivers. The conversion of coordinates between different reference systems is only possible using empirical formulae, the validity of which is limited to restricted areas [Selvini and Guzzetti 1999]. In particular, the Aeolian Archipelago area pertains to a nonoverlaying zone between the Roma 1940 Datum adopted in the Gauss Boaga reference system and the WGS 1984 datum: as a consequence, the conversion of the coordinates between 
these two systems is affected by pseudo-random errors that can show magnitude changes within a single island of the archipelago of from a few meters to several hundreds of meters. From a theoretical point of view, this problem can be solved via new georeferencing of the non-WGS1984 map using the GPS coordinates of some of the points that are visible both on the map and on the terrain. In the specific case of the La Fossa crater, this solution is not possible because the old base map covers a very restricted area that is centered on the crater

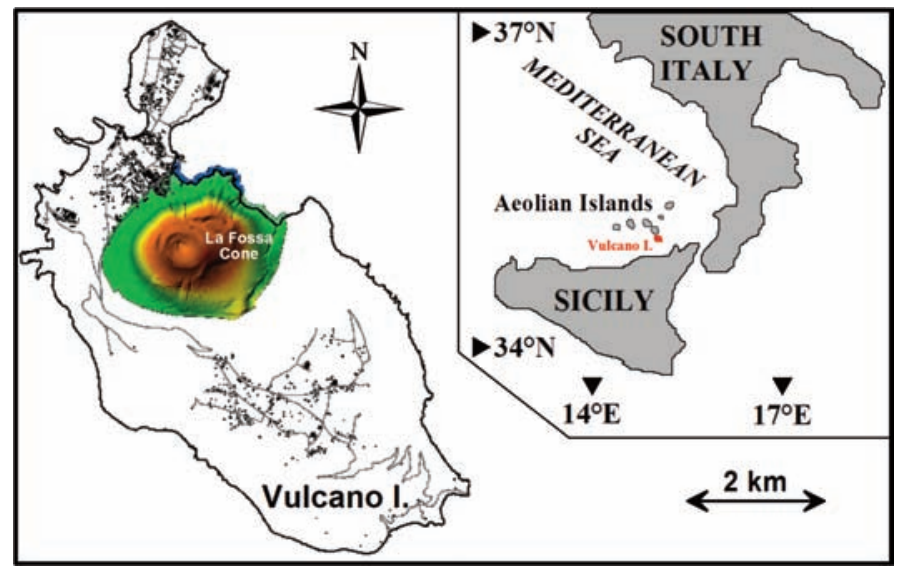

Figure 1. Location of Vulcano Island and the La Fossa cone. and that has no fixed points that can be recognizable on the terrain. The only chance for correct coordinate conversion is the evaluation of the spatial distribution of the conversion errors at Vulcano Island: if the errors are not randomly distributed, but driven by gradients described via statistical functions, it will then be possible to correct them and to move the data from the Roma 1940 to the WGS 1984 Datum.

The present study undertakes this procedure, which is applied for the conversion of the historical fumarole positions at the La Fossa crater, to allow for their comparison with newly acquired data based on GPS methods. The main aim of this report is to bridge together the cartographic and geochemical field procedures, to give to geochemists, who are generally not used to coping with the details of cartographical techniques, information about the correct field procedures for the comparison of old surveys with new GPS-based data. Moreover, the GPS-based map presented in this study is the first cartographic update of the La Fossa crater fumarolic field since the end of the 1990's.

\section{Materials and methods}

The digital raster and vector data used in this study were from the GNV-DPC Project 2000-03 n 13, Task 2 (Application of Digital Terrain Models To Volcanology; Coordinator: M. Coltelli). In particular, we used section $n^{\circ} 581160$ of the Sicilian

\begin{tabular}{|c|c|c|c|c|c|c|c|}
\hline Id & Easting GPS & Northing GPS & Easting (calc) & Northing (calc) & $\Delta \mathrm{E}(\mathrm{m})$ & $\Delta \mathrm{N}(\mathrm{m})$ & $\Delta \mathrm{pos}(\mathrm{m})$ \\
\hline V01 & 496547 & 4253140 & 496486 & 4253139 & 61 & 1 & 61 \\
\hline V02 & 496195 & 4253340 & 496129 & 4253332 & 66 & 8 & 66 \\
\hline V03 & 496334 & 4252440 & 496286 & 4252439 & 48 & 1 & 48 \\
\hline V04 & 496958 & 4252929 & 496902 & 4252933 & 56 & -4 & 56 \\
\hline V05 & 496677 & 4251896 & 496639 & 4251901 & 38 & -5 & 38 \\
\hline V06 & 495856 & 4252327 & 495813 & 4252322 & 43 & 5 & 44 \\
\hline V07 & 495972 & 4251629 & 495937 & 4251622 & 35 & 7 & 36 \\
\hline V08 & 495762 & 4250945 & 495738 & 4250936 & 24 & 9 & 26 \\
\hline V09 & 494948 & 4251111 & 494921 & 4251095 & 27 & 16 & 31 \\
\hline V10 & 495558 & 4250059 & 495547 & 4250052 & 11 & 7 & 13 \\
\hline V11 & 496980 & 4250556 & 496959 & 4250564 & 21 & -8 & 23 \\
\hline V12 & 497064 & 4249194 & 497105 & 4249181 & -41 & 13 & 43 \\
\hline V13 & 499014 & 4249406 & 499009 & 4249447 & 5 & -41 & 41 \\
\hline V14 & 497773 & 4248396 & 497792 & 4248407 & -19 & -11 & 21 \\
\hline V15 & 498941 & 4248009 & 498956 & 4248046 & -15 & -37 & 40 \\
\hline V16 & 499513 & 4246737 & 499542 & 4246783 & -29 & -46 & 54 \\
\hline V17 & 499969 & 4247920 & 499998 & 4247969 & -29 & -49 & 57 \\
\hline V19 & 495642 & 4251493 & 495611 & 4251479 & 31 & 14 & 34 \\
\hline
\end{tabular}

Table 1. Measured GPS points (UTM WGS 1984) acquired during the July 27, 2008, survey. The calculated values (calc) are from the transformation of the original Gauss Boaga coordinates taken from the georeferenced CTR map of Vulcano Island; $\triangle \mathrm{E}, \triangle \mathrm{N}$ and $\Delta$ pos are the residuals between the measured and calculated Easting, Northing and position, respectively. 
regional technical cartography (Cartografia Tecnica Regionale; CTR) at the 1:10,000 scale, the digital terrain models of the La Fossa crater, and the shape-files containing the coastline, main roads and buildings. Coordinate conversions were carried out using Cartlab (release 1.2), one of the best softwares for performing coordinate conversions specifically realized for cartographical operations in the Italian territory [Travaglini 2004]. Coordinate capture and georeferencing, and map overlaying operations were performed using Quantum GIS software (release 1.0.2). Field acquisition of coordinates was carried out using a pair of Thales Magellan single frequency GPS receivers, with an external L1 antenna, in both stand-alone and differential configurations. Differential correction was calculated using the Thales Mobile Mapper Office software. Residuals between the calculated and measured coordinates were elaborated with the Kriging algorithm, using Golden Software Surfer (release 8). Regression analysis was carried out using Golden Software Grapher (release 7) software.

\section{Data presentation and discussion}

A first single GPS survey aimed as a preliminary investigation of the position error distribution was carried out on July 27,2008 . The positions of 18 points hat were visible both on the CTR map and in the field are reported in Table 1 and Figure 2, together with their calculated coordinates (derived from the georeferenced Gauss Boaga CTR map) and the residuals between their measured and calculated coordinates. As shown in Table 1, the position

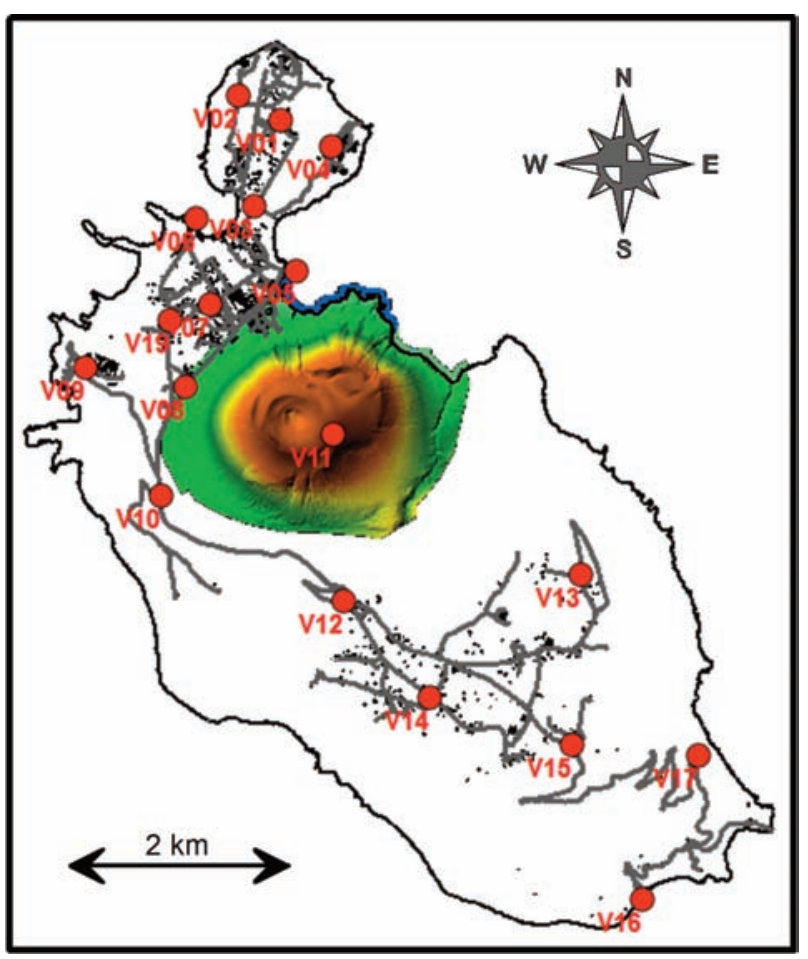

Figure 2. Positions of the GPS points acquired during the July 2008 survey at Vulcano Island (V01-V17; red circles). Gray lines, main roads; black polygons, buildings; colored shaded relief, the La Fossa cone.
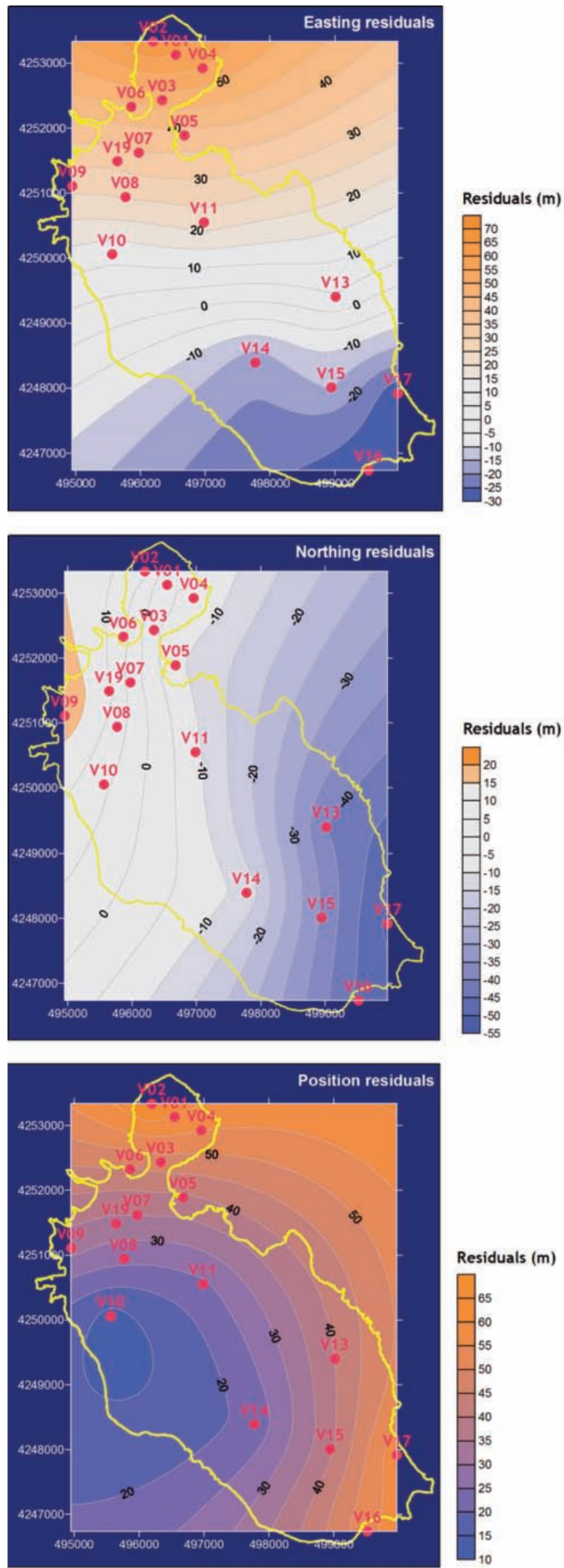

Figure 3. Maps of Easting (top), Northing (center) and position (bottom) residuals between the measured and calculated UTM WGS 1984 coordinates for the single GPS survey of July 27, 2008, at Vulcano Island. Red circles (V01-V17), GPS points. 
errors span from a minimum of $13 \mathrm{~m}$ to a maximum of 61 $\mathrm{m}$. Easting, Northing and position errors were then plotted and contoured into a map, with the aim of verifying whether their distributions are random or follow a structured behavior. The maps of the residuals are plotted in Figure 3; around the La Fossa cone area, which is the main target of our study, they follow well structured spatial patterns with gradient-like variations.

Once it was known that the position residual distributions are organized in structured patterns, and it was thus possible to calculate the statistical empiric formulae for their modeling, a second differential GPS survey was carried out, on August 28, 2008. This concentrated on measuring points in the more restricted surroundings of the La Fossa

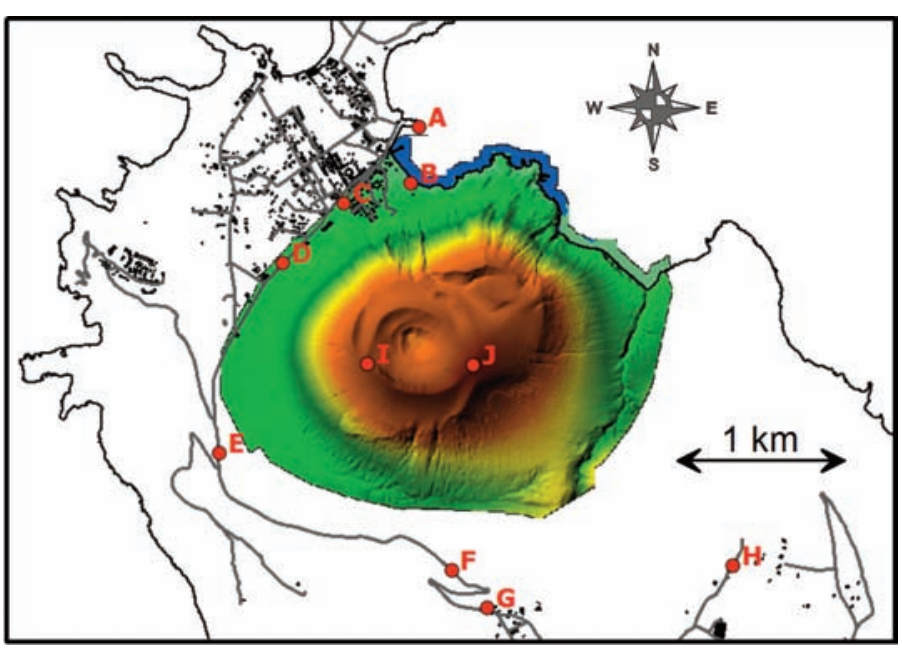

Figure 4. Positions of the GPS points acquired during the August 2008 survey at Vulcano Island (A-J; red circles). Gray lines, main roads; black polygons, buildings; colored shaded relief, the La Fossa cone. cone (Figure 4). The results of this survey are summarized in Table 2 and Figure 5. The contour map of the position errors confirmed the coherent distribution of the residuals, which were then used to calculate (via linear regression) the empirical statistical laws that describe the spatial distribution of the position errors, in terms of:

$$
\Delta \mathrm{E}=f(\text { Northing })
$$

and

$$
\Delta \mathrm{N}=f(\text { Easting })
$$

where

$$
\begin{aligned}
& \Delta \mathrm{E}=\mathrm{E}_{\text {measured }}-\mathrm{E}_{\text {converted }} \\
& \Delta \mathrm{N}=\mathrm{N}_{\text {measured }}-\mathrm{N}_{\text {converted }} .
\end{aligned}
$$

The best-fit curves are reported in Figure 6, the equations for which are:

$$
\Delta \mathrm{E}=0.01351864 \times \text { Northing }_{(\text {calculated })}-57442.7, \mathrm{r}^{2}=0.968
$$

$\Delta \mathrm{N}=-0.01410170 \times$ Easting $_{(\text {calculated) }}+6998.37, \mathrm{r}^{2}=0.977$

The residuals calculated from these equations can be used for correction of the converted coordinates of a generic point, as follows:

$$
\begin{gathered}
\mathrm{E}_{\text {corrected }}=\mathrm{E}_{\text {converted }}+\Delta \mathrm{E} \\
\mathrm{N}_{\text {corrected }}=\mathrm{N}_{\text {converted }}+\Delta \mathrm{N}
\end{gathered}
$$

\begin{tabular}{ccccccccc}
\hline Id & Easting GPS & Northing GPS & Position Error $(\mathrm{m})$ & Easting (calc) & Northing $(\mathrm{calc})$ & $\Delta \mathrm{E}(\mathrm{m})$ & $\Delta \mathrm{N}(\mathrm{m})$ & $\Delta \mathrm{pos}(\mathrm{m})$ \\
\hline A & 496677.3 & 4251894.9 & 1.3 & 496641 & 4251898 & 36.3 & -3.1 & 36.4 \\
B & 496636.2 & 4251576.7 & 4.2 & 496605 & 4251581 & 31.2 & -4.3 & 31.5 \\
C & 496257.9 & 4251466.6 & 2.9 & 496225 & 4251469 & 32.9 & -2.4 & 32 \\
D & 495912.8 & 4251131.6 & 2.5 & 495888 & 4251125 & 24.8 & 6.6 & 25.6 \\
E & 495557.6 & 4250061.6 & 2.8 & 495547 & 4250052 & 10.6 & 9.6 & 14.3 \\
F & 496861 & 4249406.6 & 1.7 & 496855 & 4249415 & 6 & -8.4 & 10.3 \\
G & 497062.9 & 4249192.5 & 3.8 & 497066 & 4249201 & -3.1 & -8.5 & 9 \\
H & 498439.9 & 4249433.1 & 4.1 & 498435 & 4249465 & 4.9 & -31.9 & 32.3 \\
I & 496357.1 & 4250599.2 & 1.6 & 496336 & 4250601 & 21.1 & -1.8 & 21.1 \\
J & 496981.2 & 4250554.9 & 2.7 & 496958 & 4250564 & 23.2 & -9.1 & 24.9 \\
\hline
\end{tabular}

Table 2. Measured GPS points (UTM WGS 1984) acquired during the August 28, 2008, survey. The calculated values (calc) are from the transformation of the original Gauss Boaga coordinates taken from the georeferenced CTR map of Vulcano Island; $\Delta \mathrm{E}, \Delta \mathrm{N}$ and $\Delta$ pos are the residuals between the measured and calculated Easting, Northing and position, respectively. 
The original Gauss Boaga maps of the fumarolic field were then converted into the UTM WGS1984 system, following the below-described procedure:

- The four Gauss Boaga pairs of the coordinates of the map vertices were converted into UTM WGS1984.
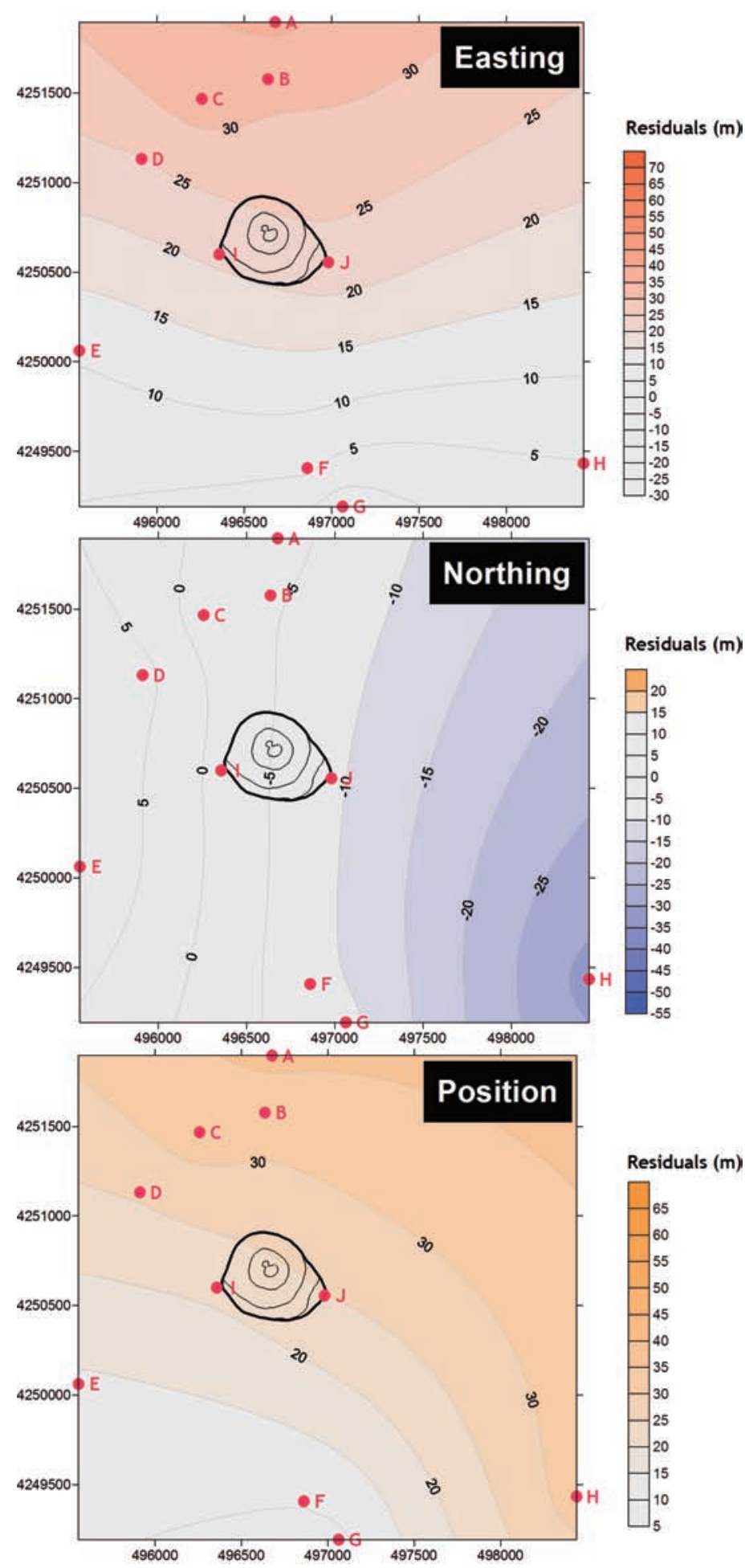

Figure 5. Maps of Easting, Northing and position residuals between the measured and calculated UTM WGS 1984 coordinates for the differential GPS survey of August 28, 2008, at Vulcano Island. Thick black line, the La Fossa crater rim; gray lines, elevation contour lines $(10 \mathrm{~m}$ contour interval). Red circles (A-J), GPS points.

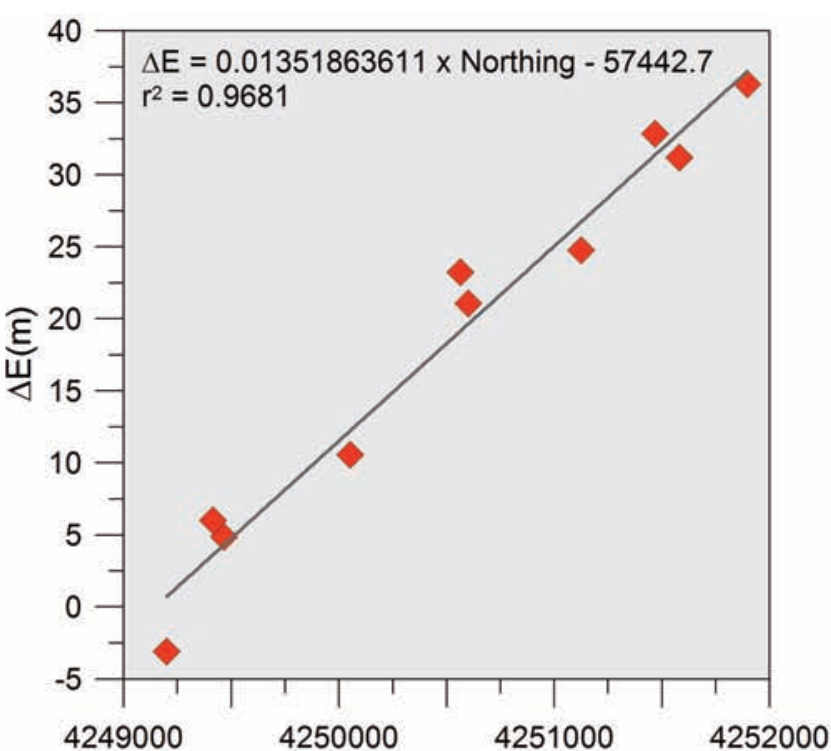

Northing UTM WGS84 (migrated from Gauss Boaga)

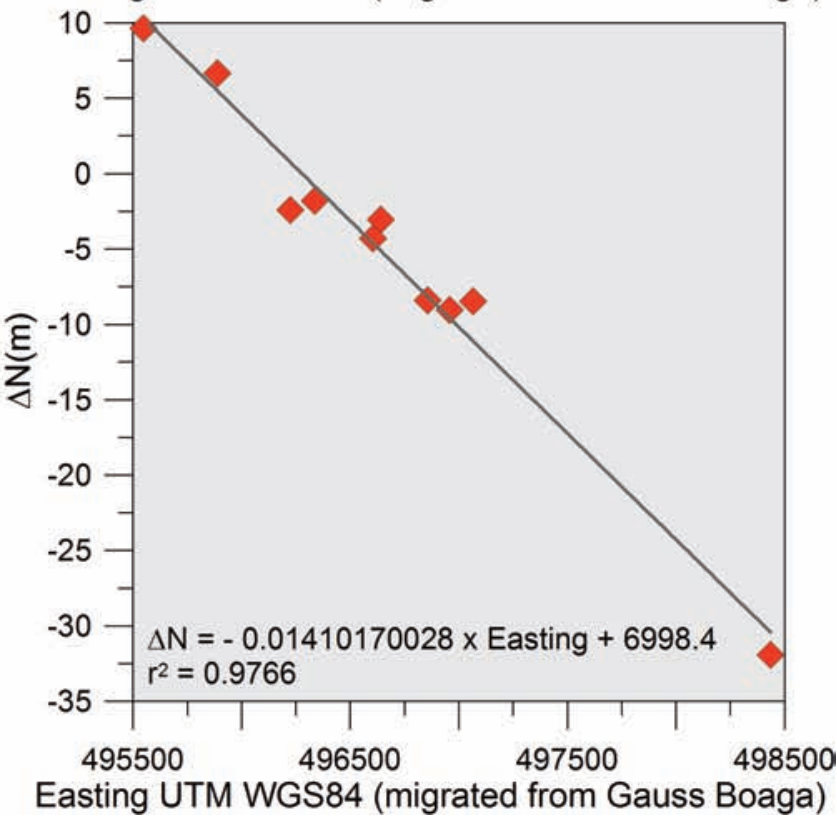

Figure 6. Best fits via linear regression of Easting residuals versus Northing (top), and Northing residuals versus Easting (bottom).

- The raw values were corrected using the abovementioned formulae.

- The corrected values were used for a new georeferencing of the fumarole maps using the rototranslation algorithm (Helmert).

The logical flow-chart of the whole procedure is shown in Figure 7, and in Table 3 we report all of the values used for the calculations. As indicated by the signs of the Easting and Northing residuals showed in Table 3, the uncorrected converted maps were expected to be shifted westwards and northwards with respect to the correct WGS 1984 positions. As also highlighted in Figure 8, once the converted and corrected maps were overlaid on the WGS 1984 base map (CTR), the Northing shifting between them was clearly compensated for, while the Easting error was apparently 


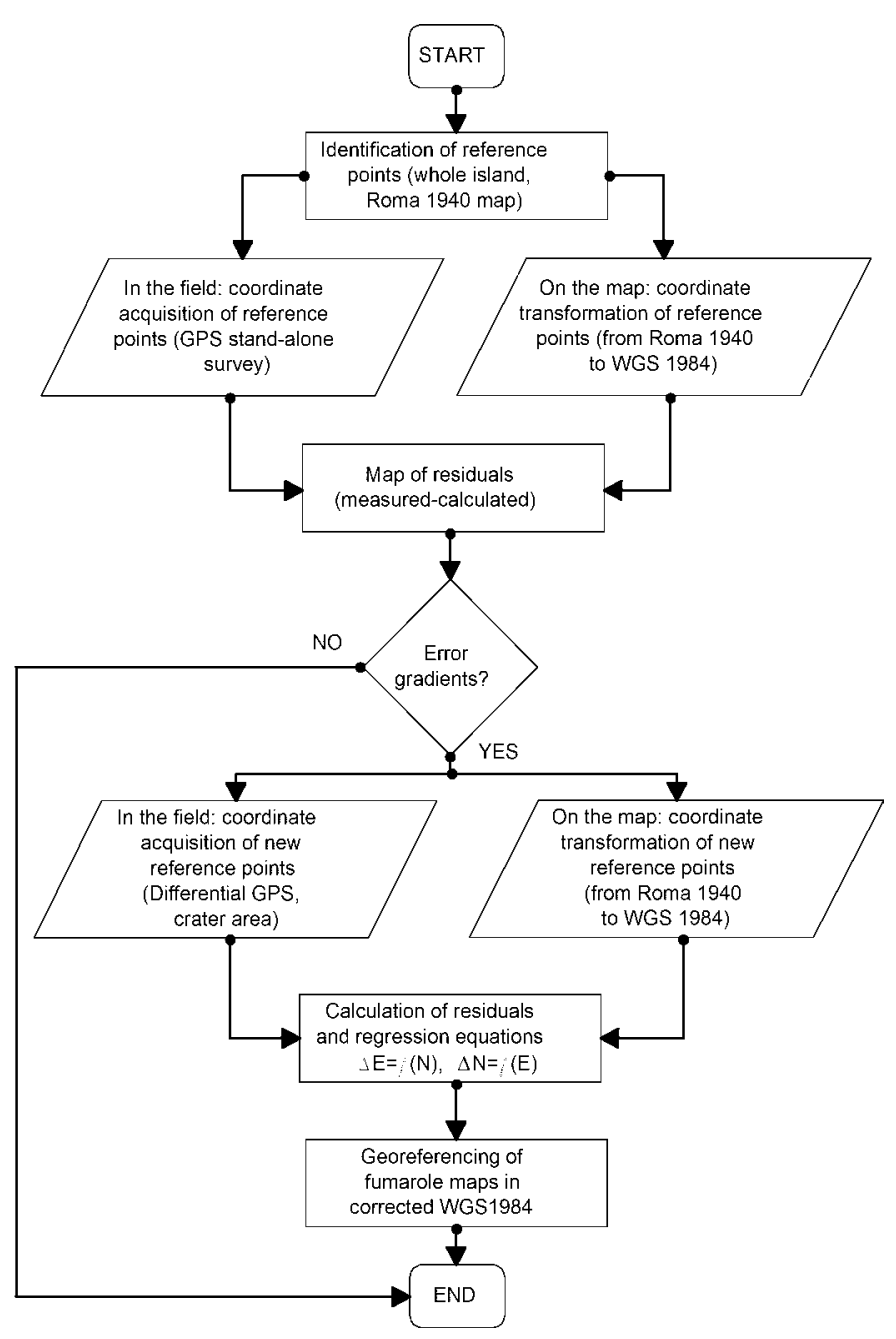

Figure 7. Logical flow-chart summarizing the whole coordinate conversion process.

\begin{tabular}{ccccc}
\hline & NW & SW & SE & NE \\
\hline Easting Gauss Boaga & 2516550 & 2516550 & 2516880 & 2516880 \\
Northing Gauss Boaga & 4250950 & 4250700 & 4250700 & 4250950 \\
$\begin{array}{c}\text { Easting WGS 1984 } \\
\text { uncorrected }\end{array}$ & 496551 & 496551 & 496881 & 496881 \\
$\begin{array}{c}\text { Northing WGS 1984 } \\
\text { uncorrected }\end{array}$ & 4250949 & 4250699 & 4250699 & 4250949 \\
E & 24 & 21 & 21 & 24 \\
N & -4 & -4 & -8 & -8 \\
$\begin{array}{c}\text { Easting WGS 1984 } \\
\text { corrected }\end{array}$ & 496575 & 496572 & 496902 & 496905 \\
$\begin{array}{c}\text { Northing WGS 1984 } \\
\text { corrected }\end{array}$ & 4250945 & 4250695 & 4250691 & 4250941 \\
\hline
\end{tabular}

Table 3. Original Gauss Boaga pairs of coordinates for the four quoted corners reported in the maps of Bukumirovic et al. [1997], as uncorrected WGS 1984 converted values, $\Delta \mathrm{E}$ and $\Delta \mathrm{N}$ calculated with Equations (5) and (6), and corrected WGS 1984 values.

doubled after the correction. This is shown by the positions of the flat bottom of the La Fossa crater, the only feature

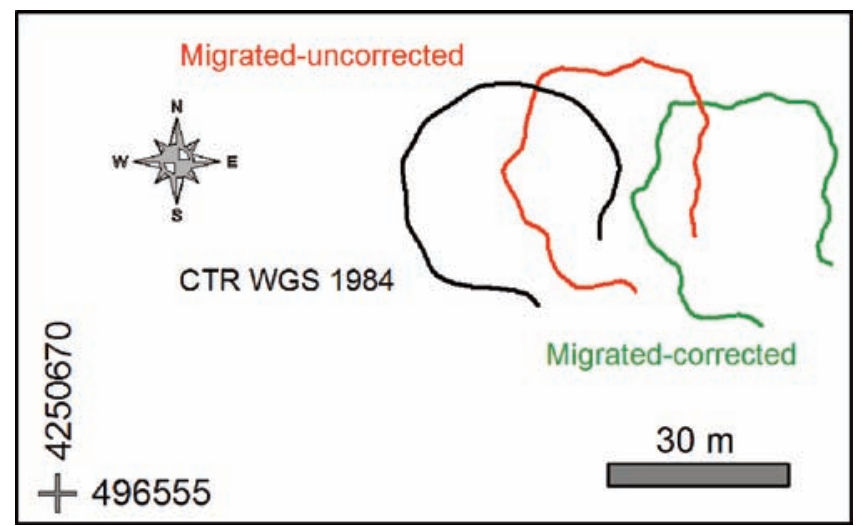

Figure 8. Relative positions of the flat bottom of the La Fossa crater from the CTR map georeferenced in WGS 1984 (black line), the uncorrected Gauss Boaga map converted in WGS 1984 (red line), and the uncorrected Gauss Boaga map corrected using the formulae presented in this study (green line).

\begin{tabular}{ccccc}
\hline & NW & SW & SE & NE \\
\hline Easting & 496538 & 496535 & 496865 & 496868 \\
Northing & 4250945 & 4250695 & 4250691 & 4250941 \\
\hline
\end{tabular}

Table 4. Final UTM WGS 1984 pairs of coordinates for the four quoted corners reported in the maps of Bukumirovic et al. [1997]; values refer to the $33 \mathrm{~S}$ Zone.

present in both the Gauss-Boaga and CTR maps, even if there are some differences due to the different nominal scales of the maps. This behavior can be explained by an Easting shifting on the original Gauss Boaga maps due to an error either in their georeferencing or in the original base map used by Bukumirovic et al. [1997]. Considering that the fumarole maps were realized taking into account the relative positions between the fumaroles and the most evident morphological features in their surroundings, we corrected the residual shift by measuring the average Easting differential between the perimeter of the flat bottom of the crater reported in the CTR and its equivalent in the converted and corrected Gauss Boaga maps. An average of $37 \mathrm{~m}$ was found, and this was subtracted from the Easting of the four vertex coordinates of the fumarole maps. The final coordinates are reported in Table 4.

The final map illustrated in Figure 9 shows the positions (red polygons) of the converted uncorrected fumaroles from Bukumirovic et al. [1997] and the same fumaroles after the corrections (blue polygons). The grey crosses are the points used to correct the CRT map (Table 4).

In October 2009, a new differential GPS survey was carried out to locate the present boundaries of almost all of the fumaroles in GPS. The fumarole boundaries obtained from the GPS survey are shown in Figure 9 as yellow polygons. The corrected positions of the non-GPS maps and the new GPS locations are relatively coincident, with errors 


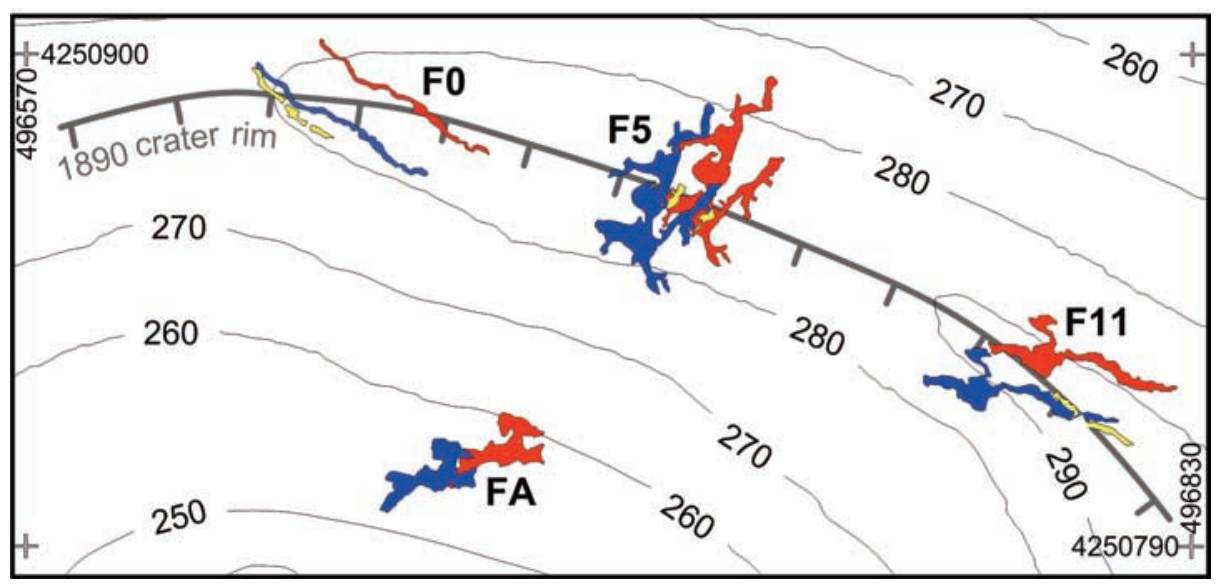

Figure 9. Fumarole positions. Red, converted uncorrected areas; blue, corrected areas; yellow, results from the new GPS survey carried out in October 2009; gray crosses, points used for georeferencing; black lines, elevation contour lines in $\mathrm{m}$ a.s.l.

no greater than $5 \mathrm{~m}$, which highlights the good quality of the previous surveys despite being carried out without the use of accurate topographical instruments.

\section{Conclusions}

The conversion of the fumarolic field maps from the original Gauss Boaga system to the UTM WGS 1984 system required not only the spatial modeling of the conversion error, but also further elaboration due to an unexpected shifts in the Easting coordinates. This is seen by the morphological comparison of the crater area as reported in the old [Bukumirovic et al. 1997] and new (CTR) maps. Such difficulties are not so uncommon during the conversion of old maps that were acquired using local positioning techniques, to provide the modern GPS equivalent.

Future mapping of this fumarolic field will be carried out using stand-alone, single-frequency GPS, as the use of more precise systems, like differential geodetic GPS, are not suitable for this specific application due to the severe operating conditions. On this basis, the map of the fumarolic field presented here, which correctly refers to the WGS 1984 reference system with errors that are compatible with those that affect stand-alone GPS surveys, represents a fundamental reference for the comparison of new data aimed to describe the evolution of the volcanic activity at the La Fossa cone.

Acknowledgements. The authors thank Fawzi Doumaz (INGV) and another anonymous reviewer for the improvements in our manuscript that arose from their suggestions.

\section{References}

Barberi, F., F. Innocenti, G. Ferrara, J. Keller and L. Villari (1974). Evolution of Eolian arc volcanism (southern Tyrrhenian Sea), Earth Planet. Sci. Lett., 21, 269-276.

Bukumirovic T., F. Italiano and P.M. Nuccio (1997). The evolution of a dynamic geological system: the support of a
GIS for geochemical measurements at the fumarole field of Vulcano, Italy. J. Volcanol. Geoth. Res., 79, 253-263.

Granieri D., M.L. Carapezza, G. Chiodini, R. Avino, S. Caliro, M. Ranaldi, T. Ricci and L. Tarchini (2006). Correlated increase in $\mathrm{CO}_{2}$ fumarolic content and diffuse emission from La Fossa crater (Vulcano, Italy): Evidence of volcanic unrest or increasing gas release from a stationary deep magma body? Geophys. Res. Lett., 33, L13316, doi:10.1029/2006GL026460.

Italiano, F. and P.M. Nuccio (1992). Volcanic steam output directly measured in the fumaroles: the observed variations at Vulcano Island, Italy, between 1983 and 1987, B. Volcanol., 54, 623-630.

Italiano, F., P.M. Nuccio and G. Pecoraino (1998). Steam output from the fumaroles of an active volcano: Tectonic and magmatic-hydrothermal controls on the degassing system at Vulcano (Aeolian arc), J. Geophys. Res., 103, B12, 29829-29842.

Selvini, A. and F. Guzzetti, (1999). Cartografia generale teorica e numerica, UTET, Torino, 143-179.

Travaglini, D. (2004). Trasformazioni tra sistemi di coordinate: software disponibili, limiti e potenzialità, Forest@, 1(2), 128-134, [online] url: http: / / www.sisef.it/. Ventura, G. (1994). Tectonics, structural evolution and caldera formation on Vulcano Island (Aeolian Archipelago, southern Thyrrenian Sea), J. Volcanol. Geoth. Res., 60, 207-224.

\footnotetext{
${ }^{\star}$ Corresponding author: Paolo Madonia, Istituto Nazionale di Geofisica e Vulcanologia, sezione di Palermo, Palermo, Italy; e-mail: p.madonia@pa.ingv.it

C 2011 by the Istituto Nazionale di Geofisica e Vulcanologia. All rights reserved.
} 